\title{
Validity of Steiner's Automobile Anxiety Inventory
}

\author{
Zack Z. Cernovsky, Milad Fattahi, Larry C. Litman, Silvia Tenenbaum, Beta Leung, \\ Vitalina Nosonova, Crystal Zhao, and Manfred Dreer
}

\section{ABSTRACT}

Background: Steiner's Automobile Anxiety Inventory (AAI) is a 23 item questionnaire which provides a quantitative measure of vehicular anxiety (amaxophobia), common in survivors of motor vehicle accidents (MVAs). The present study examines criterion and convergent validity of the AAI.

Method: De-identified data from a sample of 50 patients (mean age=39.1, $\mathrm{SD}=12.1 ; 17$ men, 33 women) injured in high impact MVAs included the scores on Steiner's AAI, as well as the pain ratings on the Brief Pain Inventory (BPI), scores on the Insomnia Severity Index (ISI), the Rivermead Post-Concussion Symptoms Questionnaire, Subjective Neuropsychological Symptoms Scale (SNPSS), Whetstone Vehicle Anxiety Questionnaire, and on Driving Anxiety Questionnaire (DAQ). The patients' scores were compared to de-identified AAI data of 22 normal controls (mean age $=45.9, \mathrm{SD}=21.3 ; 10 \mathrm{men}, 12$ women).

Results: Mean score of the patients on Steiner's AAI (mean=15.0, $\mathrm{SD}=2.5$ ) was significantly higher than the one of normal controls (mean=3.2, $\mathrm{SD}=3.8)$ in a $\mathrm{t}$-test $(\mathrm{t}=\mathbf{1 5 . 6}, \mathrm{df}=\mathbf{7 0}, \mathrm{p}<.001)$. The underlying correlation is very high $(r=.88)$ : this indicates an excellent criterion validity. Satisfactory convergent validity is suggested by significant correlations $(p<.001)$ of Steiner's AAI scores to the Whetstone Vehicle Anxiety Questionnaire $(r=.58)$ and Driving Anxiety Questionnaire $(r=.52)$. The AAI correlated at $\mathrm{p}<.001$ with post-accident neuropsychological impairments as measured by Rivermead $(r=.89)$ and SNPSS $(r=.72)$. Internal consistency of the AAI is satisfactory (Cronbach alpha $=.95)$.

Discussion and Conclusion: The results indicate satisfactory criterion and convergent validity of the Automobile Anxiety Inventory.

Keywords: Driving Anxiety, Amaxophobia, Convergent Validity, Criterion Validity.

Published Online: January 15, 2021

ISSN: $2593-8339$

DOI: 10.24018 /ejmed.2021.3.1.661

\section{Z. Z. Cernovsky*}

Western University, London, Ontario, Canada.

(e-mail: zcernovs@uwo.ca)

M. Fattahi

(M. Psy. student) Adler Graduate Professional School, Toronto, Ontario, Canada.

L. C. Litman

Western University, London, Ontario, Canada.

\section{S. Tenenbaum}

Dalla Lana School of Public Health, University of Toronto, Canada.

B. Leung

Therapist, Toronto, Ontario, Canada. V. Nosonova

Medex Assessments, Toronto, Ontario, Canada.

C. Zhao

Therapist, Ottawa, Ontario, Canada. M. Dreer

Therapist, London, Ontario, Canada.

*Corresponding Author

\section{INTRODUCTION}

Many survivors of motor vehicle accidents (MVAs) experience subsequently an excessive anxiety as drivers or passengers. Their anxiety in cars may last even several months or years and may reach the level of amaxophobia (vehicular anxiety) which impairs their quality of life. It is of advantage for psychotherapists of these patients to be able to assess rapidly but systematically the scope and particular pattern of the driving anxiety of a particular patient without missing some relevant details. For example, some patients are more anxious as drivers, but some others as passengers, for some most critical situations are on high speed highways, for some others the intersections, and yet some other persons are most nervous when driving in the rain. Some become anxious, after their MVA, also as pedestrians when crossing the street or walking next to roadways.

Very few measures of amaxophobia are available for clinical assessments of post-MVA patients. The most comprehensive is the Whetstone Vehicle Anxiety Questionnaire [1]. It consists of 31 items to assesses anxiety in various driving situations, the physical manifestations of anxiety, avoidance of driving, and related challenges. The Whetstone's questionnaire consists of items such as "As a driver, I am very concerned when vehicles following behind are close," "I take alternate routes to avoid highways, intersections, or locations," "My sleep is interrupted by thoughts of driving or of collisions," and "I feel others don't understand my fears of being in a vehicle."

The criterion validity of the Whetstone questionnaire is excellent: post-MVA patients scored significantly higher $(\mathrm{r}=.88)$ than normal controls. The highest Whetstone score of the controls was 19 and the lowest of the patients was 23: there was no overlap between the two groups.

With respect to convergent validity, the scores on Whetstone questionnaire were significantly correlated to the Driving Anxiety Questionnaire ( $\mathrm{r}=.80)$, [1] to the PCL-5 [2] measure of PTSD symptoms $(\mathrm{r}=.78)$, and to typical 
symptoms from high impact MVAs: the post-concussion syndrome ( $\mathrm{r}=.63)$ as assessed by the Rivermead scale, whiplash symptoms $(\mathrm{r}=.46)$ as assessed by the Post-MVA Neurological Symptoms scale, scores on the Insomnia Severity Index $(r=.56)$, ratings of post-MVA pain on the Brief Pain Inventory (rs ranging from .43 to .51), and ratings of post-MVA depression ( $\mathrm{r}=.40)$ and of generalized anxiety $(\mathrm{r}=.43)$ as assessed by items 10 and 12 of the Whiplash Disability Questionnaire. The Whetstone questionnaire is also available in German, Spanish, and Arabic.

The Driving Anxiety Questionnaire (DAQ) lists various driving situations: the patient is to rate the intensity of anxiety in these situations when he or she is a driver and then also separately as a passenger. The questionnaire also includes 7 items indicative of anxiety as a driver (e.g., checking blind spots too often) and 6 items indicative of passenger anxiety (e.g., the passenger's urge to press the foot on the floor to "brake"). A satisfactory convergent validity of the DAQ is suggested by its high correlation to the Whetstone questionnaire[1] (as already mentioned, $\mathrm{r}=.80$ ) and also to clinical symptoms usually experienced for months or years after high impact MVAs: the postconcussion scores on the Rivermead questionnaire [3] $(\mathrm{r}=.46)$, whiplash symptoms $(\mathrm{r}=.35)$ as assessed by the PostMVA Neurological Symptoms scale [4], scores on the Insomnia Severity Index[5] $(\mathrm{r}=.56)$, ratings of post-MVA pain on the Brief Pain Inventory[6] (rs ranging from .44 to .58), PCL-5 [2] scores ( $\mathrm{r}=.63)$, and ratings of post-MVA depression $(\mathrm{r}=.40)$ and of generalized anxiety $(\mathrm{r}=.30)$ as assessed by items 10 and 12 of the Whiplash Disability Questionnaire [7].

The text of all DAQ items is reproduced in Whetstone et al. [1].

The Automobile Anxiety Inventory (AAI) [8] was developed by Canadian psychologist Leon Steiner. His AAI is best suited for an assessment of the relative change in the level of anxiety after the MVA. Most of Steiner's items are placed within the following context "Since the accident, are you more nervous when ...." Steiner's AAI is a 23 item questionnaire of which 18 are scored to provide a quantitative measure of post-MVA vehicular anxiety (amaxophobia), see the full text in Table 1. The initial study of the AAI reported satisfactory convergent validity: Pearson $\mathrm{r}$ of .50 to DAQ, .45 to Whetstone [1], .57 to the PCL-5 measure of PTSD symptoms [2], .34 to the postconcussion syndrome as assessed by the Rivermead scale [3], and .45 to whiplash symptoms as assessed by the PostMVA Neurological Symptoms scale [4].

The advantage of Steiner's questionnaire is its brevity. The items are worded in simple English, thus making it suitable even for clients who read rarely or reluctantly, or for persons whose grasp on English is tenuous.

The items listed in italics in Table 1 are not scored: they are included only to provide potentially relevant information for psychotherapists, but their content is not necessarily indicative of the intensity of amaxophobia.
TABLE 1: LEON STEINER'S AUTOMOBILE ANXIETY INVENTORY (TOTAL SCORE IS BASED ON ALL ITEMS EXCEPT THOSE LISTED IN ITALICS)

\begin{tabular}{|c|c|c|}
\hline & Plea & cle: \\
\hline $\begin{array}{l}\text { 1. Are you more nervous in an automobile since your } \\
\text { accident? }\end{array}$ & Yes & No \\
\hline Do you have a motor vehicle license? & Yes & No \\
\hline Have you driven a car since your accident? & Yes & No \\
\hline 2. Do you avoid driving whenever possible? & Yes & No \\
\hline $\begin{array}{l}\text { 3. Do you drive much slower or more carefully since } \\
\text { your accident? }\end{array}$ & Yes & No \\
\hline $\begin{array}{l}\text { Have you been a passenger in a car since your } \\
\text { accident? }\end{array}$ & Yes & No \\
\hline $\begin{array}{l}\text { 4. Do you avoid being a passenger in a car whenever } \\
\text { possible? }\end{array}$ & Yes & No \\
\hline 5. Are you more nervous in a car after nightfall? & Yes & No \\
\hline 6. Are you more nervous in traffic? & Yes & No \\
\hline 7. Are you more nervous traveling on a highway? & Yes & No \\
\hline 8. Are you more nervous in an intersection? & Yes & No \\
\hline $\begin{array}{l}\text { 9. Are you more nervous when outside the immediate } \\
\text { area of your home? }\end{array}$ & Yes & No \\
\hline $\begin{array}{l}\text { 10. Are you more nervous in the rain or in bad weather } \\
\text { conditions? }\end{array}$ & Yes & No \\
\hline
\end{tabular}
conditions?

Please circle: Are you more nervous as a driver, or as a passenger, or no difference

11. Are you more nervous when certain people are in Yes No the car with you?

Please explain your response to the Item 11:

12. Are you more nervous when other vehicles are in

your immediate proximity?

13. Are you more nervous when you hear the sound of a car horn or brakes?

14. Are you more nervous when you pass the scene of the accident?

15. Are you more nervous as a pedestrian? Yes No

If yes, are you more nervous (please circle): on sidewalks, or crossing streets or both

16. Do you keep thinking about the accident when you Yes No are in a car? 17. Do you often feel that you are about to have Yes No
another accident?

18. Do you feel sometimes that you will never regain your former confidence?

Note: The noun "licence" is spelled as "license" in the USA, but as "licence" in Canada, the UK, Ireland, Australia, New Zealand, and South Africa.

The present study evaluates the criterion validity of Steiner's AAI by comparing responses of patients injured in high speed MVAs to those of normal controls.

\section{METHOD}

De-identified archival data on Steiner's AAI were reviewed for a sample of 50 patients (17 men, 33 women) injured in high impact MVAs. Their age ranged from 19 to 70 years with the average of 39.1 years, $S D=12.1$. Their data included ratings of the worst, least, and average pain on Items 3 to 5 of the Brief Pain Inventory (BPI) [6], scores on the Insomnia Severity Index (ISI) [5], the Rivermead PostConcussion Symptoms Questionnaire,[3] Subjective Neuropsychological Symptoms Scale (SNPSS) [9], Whetstone Vehicle Anxiety Questionnaire,[1] and on the Driving Anxiety Questionnaire (DAQ). As explained earlier, the DAQ is described in the article by Whetstone et al. [1].

In their MVA, most patients were the drivers $(\mathrm{N}=37$, i.e., $74.0 \%), 5$ were passengers $(10.0 \%), 7$ were pedestrians $(14.0 \%)$, and one drove a motorcycle. Only 12 (24.4\%) lost consciousness in the MVA. Only one of these 12 patients experienced the loss of consciousness lasting longer than 5 minutes. 
The impact of the collision was to the front of the vehicle in 13 cases $(26.0 \%)$, to the side in 14 cases $(28.0 \%)$, to the rear in 13 cases $(26.0 \%)$, and more complex in the remaining cases.

The number of weeks since the collision ranged from 11 to 141 , with the average of 49.7 ( $\mathrm{SD}=30.8)$, however, all still experienced active post-MVA symptoms requiring treatment.

The patients' scores were compared to de-identified AAI data of 22 normal controls (10 men, 12 women). Their age ranged from 22 to 84 years, with the average of 45.9 years, $\mathrm{SD}=21.3$. Their responses were also available for the SNPSS and for Rivermead questionnaire.

As explained, Steiner's Automobile Anxiety Inventory (AAI) is designed for post-MVA patients. The items inquire about the relative increase of driving anxiety since the MVA. As mentioned, they are introduced in the following context: "Since the accident, are you more nervous when ...".

It was necessary to re-phrase the items to be applicable to normal controls who have not been in severe MVAs, see the revised item text in Table 2.

TABLE 2: STEINER's AUTOMOBILE ANXIETY INVENTORY, REVISED TEXT FOR NORMAL CONTROLS

\begin{tabular}{llll}
\hline & \multicolumn{2}{l}{ Please circle: } \\
\hline $\begin{array}{l}\text { 1. Do you feel nervous when you are in an } \\
\text { automobile? }\end{array}$ & Yes & No \\
Do you have a motor vehicle license? & Yes & No \\
Have you driven a car within the last year? & Yes & No \\
$\begin{array}{l}\text { 2. Do you avoid driving (car trips) whenever } \\
\text { possible? }\end{array}$ & Yes & No \\
3. Do you drive slower or more carefully than other & Yes & No \\
persons? & & \\
Have you been a passenger in a car within the last & Yes & No \\
year? & & \\
4. Do you avoid being a passenger in a car & Yes & No \\
whenever possible? & Yes & No \\
5. Are you nervous in a car after nightfall? & Yes & No \\
6. Are you nervous in traffic? & Yes & No \\
7. Are you nervous traveling on a highway? & Yes & No \\
8. Are you nervous in an intersection? & Nos \\
9. Are you nervous on car trips outside the & No \\
immediate area of your home? & \\
$\begin{array}{l}\text { 10. Are you nervous on car trips in the rain or in } \\
\text { bad weather conditions? }\end{array}$ & Yes & No \\
\hline
\end{tabular}

Please circle: Are you more nervous as a driver, or as a passenger, or it makes no difference, or you are rarely a driver

11. Are you nervous when certain people are in the Yes No

car with you?

12. Are you nervous in cars when other vehicles
are in your immediate proximity?

are in your immediate proximity?
13. Are you nervous on car trips when you hear the sound of a car horn or brakes?

14. Are you nervous on car trips when you pass the Yes No scene of an accident? 15. Are you nervous as a pedestrian near Yes No
roadways?

Please circle: As a pedestrian, are you more nervous on sidewalks, or while crossing streets,

or equally in both situations

16. Do you keep thinking about car accidents when you are in a car?

Yes $\quad$ No

17. Do you often feel that you are about to have a

car accident?

Yes No

18. Do you sometimes feel that you will never feel confident in cars?

Note: Items listed in italics were not scored.

\section{RESUlTS}

\section{A. Average Scores on Clinical Variables}

Mean scores of the post-MVA patients and those of normal controls are summarized in Table 3.

TABLE 3: MEAN SCORES ON CLINICAL VARIABLES

\begin{tabular}{|c|c|c|c|}
\hline & \multicolumn{2}{|c|}{ Average score (SD): } & \multirow[b]{2}{*}{$\begin{array}{l}\text { Point-biserial } \\
\text { correlation }\end{array}$} \\
\hline & $\begin{array}{l}\text { MVA- } \\
\text { patients }\end{array}$ & $\begin{array}{l}\text { Normal } \\
\text { controls }\end{array}$ & \\
\hline $\begin{array}{l}\text { Steiner's Automobile Anxiety } \\
\begin{array}{l}\text { Inventory }(50 \text { patients, } 22 \\
\text { controls })\end{array}\end{array}$ & $15.0(2.5)$ & $3.2(3.8)$ & $.88(\mathrm{p}<.001)$ \\
\hline $\begin{array}{l}\text { Subjective Neuropsychological } \\
\text { Symptoms Scale [9] (49 } \\
\text { patients, } 22 \text { controls) }\end{array}$ & $21.0(10.9)$ & $2.3(4.9)$ & $.68(\mathrm{p}<.001)$ \\
\hline $\begin{array}{l}\text { Rivermead Questionnaire } \\
\text { (48 patients, } 22 \text { controls) }\end{array}$ & $45.6(10.1)$ & $7.6(13.0)$ & $.85(\mathrm{p}<.001)$ \\
\hline $\begin{array}{l}\text { The following data are from } \\
\text { the patients only: }\end{array}$ & $\begin{array}{l}\text { Average } \\
\text { score } \\
(\mathrm{SD}) \text { : }\end{array}$ & & \\
\hline $\begin{array}{l}\text { Whetstone Vehicle Anxiety } \\
\text { Questionnaire [1] }(\mathrm{N}=43)\end{array}$ & $62.8(19.0)$ & & \\
\hline $\begin{array}{l}\text { Driving Anxiety Questionnaire } \\
\text { [1] }(\mathrm{N}=39)\end{array}$ & $90.0(22.9)$ & & \\
\hline $\begin{array}{l}\text { Brief Pain Inventory [6] Items } \\
3 \text { to } 5(\mathrm{~N}=50) \text { : } \\
\text { Worst pain } \\
\text { Least pain } \\
\text { Average pain }\end{array}$ & $\begin{array}{l}8.3(1.1) \\
4.4(1.5) \\
6.4(1.2) \\
\end{array}$ & & \\
\hline $\begin{array}{llll}\text { Insomnia } & \text { Severity } & \text { Index } & {[5]} \\
(\mathrm{N}=50)\end{array}$ & $24.0(3.9)$ & & \\
\hline $\begin{array}{l}\text { Whiplash Disability } \\
\text { Questionnaire [7] }(\mathrm{N}=50) \\
\text { Depression } \\
\text { Anger } \\
\text { Generalized anxiety }\end{array}$ & $\begin{array}{l}8.3(1.8) \\
8.3(1.6) \\
8.8(1.4)\end{array}$ & & \\
\hline
\end{tabular}

\section{B. Criterion Validity of Steiner's Automobile Anxiety Inventory (AAI)}

The criterion validity of a test or scale is the extent to which the test or scale indeed does what it was intended to do. In the case of Steiner's AAI (a measure of relatively abnormal automobile anxiety), the scale should differentiate patients with subjective symptoms of driving anxiety from normal controls. The scores of our patients on the AAI ranged from 8 to 18 points with an average of 15.0 points $(\mathrm{SD}=2.5)$. Those of normal controls ranged from 0 to 17 points, with an average of 3.2 points $(\mathrm{SD}=3.8)$. As listed in Table 3, this difference in mean scores corresponds to the Pearson point biserial correlation of .88, $\mathrm{p}<.001$. This indicates a very satisfactory criterion validity of Steiner's AAI.

With respect to the individual AAI items, the differences in proportion in endorsing these items are listed in Table 4.

Differences on all scored items were significant, except on Item 10 (being nervous on car trips in rain or bad weather).

\section{Internal Consistency of Steiner's Automobile Anxiety Inventory $(A A I)$}

The Cronbach alpha coefficient of internal consistency calculated for Steiner's AAI was .95, i.e., excellent. The item total correlations (correlation of each item to the sum of remaining items) ranged from .19 for Item 10 (Feeling nervous in bad weather) to .91 for Item 1 (Feeling more nervous in automobiles since the MVA). However, there would be only a negligible change in Cronbach alpha 
coefficient if any of the 18 scored items were deleted: the alpha coefficients after the deletion of any of the individual items ranged from .94 to .95 .

TABLE 4: DIFFERENCES IN RESPONDING WITH “YES” TO THE 18 SCORED ITEMS OF AAI

\begin{tabular}{|c|c|c|c|}
\hline Steiner's AAI items: & $\begin{array}{l}\% \text { of } \\
\text { patients } \\
(\mathrm{N}=50)\end{array}$ & $\begin{array}{c}\% \text { of } \\
\text { Controls } \\
(\mathrm{N}=22)\end{array}$ & $\begin{array}{l}\text { Point- } \\
\text { biserial } r\end{array}$ \\
\hline 1. Nervous in automobiles & $98.0 \%$ & $9.1 \%$ & $.90 \mathrm{p}<.001$ \\
\hline $\begin{array}{l}\text { 2. Avoiding car trips whenever } \\
\text { possible }\end{array}$ & $82.0 \%$ & $18.2 \%$ & $.61 \mathrm{p}<.001$ \\
\hline 3. Slow, careful driving & $90.0 \%$ & $40.9 \%$ & $.52 \mathrm{p}<.001$ \\
\hline $\begin{array}{l}\text { 4. Avoidance of being a } \\
\text { passenger }\end{array}$ & $72.0 \%$ & $9.1 \%$ & $.58 \mathrm{p}<.001$ \\
\hline $\begin{array}{l}\text { 5. Nervous in cars after } \\
\text { nightfall }\end{array}$ & $82.0 \%$ & $22.7 \%$ & $.57 \mathrm{p}<.001$ \\
\hline 6. Nervous in traffic & $98.0 \%$ & $4.5 \%$ & $.94 \mathrm{p}<.001$ \\
\hline 7. Nervous on highways & $88.0 \%$ & $13.6 \%$ & $.72 \mathrm{p}<.001$ \\
\hline 8. Nervous in intersections & $88.0 \%$ & $9.1 \%$ & $.76 \mathrm{p}<.001$ \\
\hline $\begin{array}{l}\text { 9. Nervous on car trips outside } \\
\text { of home neighborhood }\end{array}$ & $66.0 \%$ & $9.1 \%$ & $.52 \mathrm{p}<.001$ \\
\hline $\begin{array}{l}\text { 10. Nervous on car trips in rain } \\
\text { or bad weather }\end{array}$ & $92.0 \%$ & $81.8 \%$ & $\begin{array}{l}.15 \mathrm{p}=.105, \\
\text { n.s. }\end{array}$ \\
\hline $\begin{array}{l}\text { 11. Nervous when certain } \\
\text { people in the car }\end{array}$ & $56.0 \%$ & $9.1 \%$ & $.44 \mathrm{p}<.001$ \\
\hline $\begin{array}{l}\text { 12. Nervous when other } \\
\text { vehicles are close }\end{array}$ & $94.0 \%$ & $9.1 \%$ & $.84 \mathrm{p}<.001$ \\
\hline $\begin{array}{l}\text { 13. Nervous in cars when } \\
\text { hearing the sound of car horn } \\
\text { or brakes }\end{array}$ & $90.0 \%$ & $36.4 \%$ & $.56 \mathrm{p}<.001$ \\
\hline $\begin{array}{l}\text { 14. Nervous when passing the } \\
\text { scene of an accident }\end{array}$ & $94.0 \%$ & $13.6 \%$ & $.83 \mathrm{p}<.001$ \\
\hline $\begin{array}{l}15 . \text { Nervous as a pedestrian } \\
\text { near roadways }\end{array}$ & $40.0 \%$ & $9.1 \%$ & $.32 \mathrm{p}=.003$ \\
\hline $\begin{array}{l}\text { 16. Keeps thinking about } \\
\text { MVAs when in cars }\end{array}$ & $88.0 \%$ & $9.1 \%$ & $.76 \mathrm{p}<.001$ \\
\hline $\begin{array}{l}\text { 17. Feeling that an MVA is } \\
\text { about to happen }\end{array}$ & $90.0 \%$ & $9.1 \%$ & $.78 \mathrm{p}<.001$ \\
\hline 18. Feeling of never regaining & $84.0 \%$ & $9.1 \%$ & $.73 \mathrm{p}<.001$ \\
\hline
\end{tabular}

Note: All correlations are listed with 1-tailed significance; n.s. $=$ not significant, $\mathrm{p}>$.05, 1-tailed.

\section{Convergent validity of Steiner's Automobile Anxiety Inventory $(A A I)$}

Convergent validity is the extent to which the scores of a new scale correlate with other scales or with measures with which the new scale is theoretically expected to correlate. In the case of the AAI, positive correlations were expected with scores on the Whetstone Vehicle Anxiety Questionnaire and also on the Driving Anxiety Questionnaire. These correlations are of moderate magnitude and indicate a satisfactory convergent validity of Steiner's AAI, see Table 5.

\section{E. Correlations of Steiner's Automobile Anxiety Inventory (AAI) to Other Clinical Variables}

As shown in Table 5, Steiner's scores were not significantly related to gender: men did not differ from women with respect to levels of reported driving anxiety.

As shown in Table 5, older persons tended to report somewhat less driving anxiety $(\mathrm{r}=-.27)$, but the underlying correlation is too weak to be of clinical importance as it explains only about $7.3 \%$ of the variance in the AAI scores. It is possible that the young and less experienced drivers were more nervous while driving.

The clinical lore would suggest that patients burdened by more post-MVA symptoms would also show more driving anxiety. This expectation was not confirmed with respect to pain, with respect to insomnia, and with respect to generalized anxiety, see Table 5. However, the levels of driving anxiety were significantly correlated with postconcussion symptoms (scores on the Rivermead) and other subjective post-MVA neuropsychological symptoms (scores on the SNPSS) and also with post-MVA ratings of depression and anger, see Table 5.

TABLE 5: CORRELATIONS OF AAI SCORES TO CLINICAL VARIABLES

\begin{tabular}{|c|c|c|}
\hline & Pearson $\mathrm{r}$ & P level \\
\hline Age $(\mathrm{N}=72)$ & -.27 & .020 \\
\hline Gender $(\mathrm{N}=72)$ & .09 & .447 , n.s. \\
\hline $\begin{array}{l}\mathrm{N} \text { of previous MVAs } \\
\text { (patients only, } \mathrm{N}=50 \text { ) }\end{array}$ & .08 & .576 , n.s. \\
\hline $\begin{array}{l}\mathrm{N} \text { of weeks since accident (patients only, } \\
\mathrm{N}=50 \text { ) }\end{array}$ & -.13 & .360 , n.s. \\
\hline $\begin{array}{l}\text { Whetstone Vehicle Anxiety Questionnaire } \\
\text { [1] } \\
\text { (patients only, } N=43 \text { ) }\end{array}$ & .58 & $\mathrm{p}<.001$ \\
\hline $\begin{array}{l}\text { Driving Anxiety Questionnaire [1] } \\
\text { (patients only, N=39) }\end{array}$ & .52 & $\mathrm{p}=.001$ \\
\hline $\begin{array}{l}\text { Subjective Neuropsychological } \\
\text { Symptoms Scale (SNPSS) [9] } \\
\text { (50 patients, } 22 \text { controls) }\end{array}$ & .72 & $\mathrm{p}<.001$ \\
\hline $\begin{array}{l}\text { Rivermead Post-Concussion Symptoms } \\
\text { Questionnaire [3] } \\
\text { (48 patients, } 22 \text { controls) }\end{array}$ & .89 & $\mathrm{p}<.001$ \\
\hline $\begin{array}{l}\text { Brief Pain Inventory [6], Items } 3 \text { to } 5 \\
\text { (patients only, } N=50 \text { ): }\end{array}$ & & \\
\hline Ratings of worst pain & .09 & .532 , n.s. \\
\hline Ratings of least pain & -.09 & .556, n.s. \\
\hline Ratings of average pain & .04 & .785 , n.s. \\
\hline $\begin{array}{l}\text { Insomnia Severity Index [5] (patients } \\
\text { only, } \mathrm{N}=50 \text { ) }\end{array}$ & .27 & .055 , n.s. \\
\hline $\begin{array}{l}\text { Whiplash Disability Questionnaire [7] } \\
\text { (patients only, N=50) }\end{array}$ & & \\
\hline Ratings of depression & .36 & .010 \\
\hline Ratings of anger & .39 & .006 \\
\hline Ratings of generalized anxiety & .28 & .052 , n.s. \\
\hline
\end{tabular}

Note: The p levels are 2-tailed; n.s.=not significant in a 2-tailed test.

It is noteworthy that Steiner's AAI scores would be considered as significantly correlated with generalized anxiety and also with insomnia, if the 1-tailed test of significance is used. The 1-tailed test (i.e., a less stringent criterion) is justified when the direction of the correlation is predicted in advance, however, the size of these correlation coefficients is too small: they would probably account only for $7.3 \%$ or $7.8 \%$ of the variance in the AAI scores.

\section{DISCUSSION}

Our statistical results indicate that Steiner's Automobile Anxiety Inventory has a satisfactory criterion and convergent validity. As mentioned, the advantage of Steiner's questionnaire over other measures of amaxophobia is its brevity and relatively simple English, thus making it appropriate even for clients who read rarely or have a relatively limited English vocabulary.

The AAI was developed to allow for a relatively rapid but systematic clinical assessment of new patients. It is meant to provide the most essential information for psychotherapists. For example, it is important, in the behavior therapy of phobia, to know details such as whether or not a particular patient is more anxious as a driver or as a passenger, or also anxious as a pedestrian near vehicular traffic, and which specific driving environments trigger the anxiety. 
In addition to the "Yes" and "No" responses, the patient could be instructed by the behavior therapist to rank-order, on the left margin, the AAI items from those associated with the highest to those associated with least anxiety. This ranking would generate the particular patient's hierarchy of driving situations, ranked according to level of associated anxiety, as needed for behaviour therapy of the phobia.

The cognitive behavior therapy (CBT) consists of various, diverse approaches that can be tailored to the cognitive style of the particular patient to reduce the intensity of driving anxiety. For example, the CBT procedure of the thought record and of "challenging anxious thoughts" accelerates the healing process by gradually replacing the intrusive catastrophizing thoughts with their less extreme, more realistic equivalents. However, caution is recommended when a therapist challenges the patient's belief or perception of reality too early, it can potentially contribute to an erosion of the therapeutic alliance because the patient might feel misunderstood, harassed in an insensitive manner, or blamed and mistreated by the therapist. The patient must first be encouraged and instructed to use an open experimental stance with CBT to be able to more reasonably reflect on the catastrophizing thoughts rather than being "challenged" by the therapist in a manner that the patients might view as lacking in appropriate compassion.

Some new, inexperienced drivers and some passengers who were never involved in a serious car accident also report signs of amaxophobia. The renowned pioneer in this field of research is Joanne Taylor of Massey University, New Zealand [10]-[13]. Her research team considers that the driving fear, in some patients, maybe an extension of agoraphobia.

Driving anxiety is experienced by almost every driver in some situations, even by those who never had a serious MVA, but such anxiety is usually more intense in the new, inexperienced drivers. Psychological assessment of such new, particularly anxious drivers can be accomplished with the Driving Behavior Survey (DBS) [14]. The DBS consists of 20 items, rated on a scale from 1="never" to 7="always," for example Item 4. "I have trouble staying in the correct lane," 5. "I drift into other lanes," 6. "I forget to make appropriate adjustments in speed."

Phobic fear in novice drivers can also be evaluated with the Driving Cognition Questionnaire (DCQ) [15]. The DCQ also consists of 20 items. These items are rated on a scale from $0=$ "never" to 4="always." Some items of this questionnaire assess related self-image issues and social anxieties, e.g., Item 8. "People will think I am a bad driver," 15. "I will hold up traffic and people will be angry," 17. "People will laugh at me," and 20. "I will lose control of myself and act stupidly or dangerously." Lack of experience with driving, or lack of driving skills, or feeling of related personal inadequacy of novice drivers obviously constitutes a different psychological source of anxiety than the sudden traumatic event of a car accident that causes post-accident anxiety of drivers who were adequately self-confident in cars before the collision triggered their post-accident amaxophobia. Self-image issues about being inferior to "experienced drivers" are relatively uncommon in such postaccident patients some of whom drove without accidents and without emotional discomfort for decades.
The Driving and Riding Avoidance Scale (DRAS) [16] also consists of 20 items, scored from $0=$ "rarely or none of the time" to $4=$ "most or all of the time." These 20 items describe situations in which driving is avoided. However, as pointed out by Taylor and Sullman [13], the wording of DRAS items may elicit responses not necessarily based on fear of driving, but perhaps involving some economic or practical issues. For instance, the travel by streetcars or subway trains within some major cities is often more rapid than in cars and saves both gasoline and parking fees.

Briefly, the Steiner's AAI is designed for assessments of post-accident amaxaphobia of previously self-confident drivers who were free of excessive anxiety prior to their accident. Its task is to facilitate such assessments, making them more systematic, and providing detailed information for therapists who work with these patients.

The AAI is intended for "mapping" the individual pattern of manifestations of driving anxiety to allow systematic and quantitative routine clinical assessments of each patient. No cutoff score is provided at this time because it is theoretically feasible that a patient endorsing all 18 items might be, in an extreme case, less seriously disabled by amaxophobia than another one who marked only one or a few items with "Yes," but experiences a more adverse deterioration of the quality of daily life, when the restrictions of travel due to vehicular anxiety interfere in some extreme manner with the occupational activities, selfcare activities, and family life of the patient. Thus, the main purpose of Steiner's AAI in clinical work is to provide descriptive clinical data based on a standardized systematic assessment rather than using a quantitative diagnostic cutoff in individual cases. For example, the psychotherapist may review the patients' responses to AAI items in the counselling session to inquire about the context and nuances of avoidance of certain driving situations, the limitation in their regular participation in life due to avoidance of driving, and the impact of these factors on self-esteem or self-image. The pre- and post-accident context of the MVA must be also clarified to understand the patient's experience of the current symptoms.

Some patients find it difficult to describe their MVA related feelings in words without some prompting in a safe therapeutic relationship. Reviewing the AAI responses with the patient in the treatment sessions would facilitate emergence of nuanced information which helps the process of providing instructions for the use of exposure therapy appropriately customized for the individual patient. The nuanced information may also assist the patient in learning more about the underlying limiting cognitions, and later to reflect and evaluate the negative automatic thoughts associated with strong emotions during the cognitive reappraisal. Briefly, Steiner's AAI may serve as a tool in therapy of post-MVA patients.

The AAI is available in the German, Spanish, Russian, Mandarin Chinese, and Czech translations.

\section{Conclusions}

The results indicate satisfactory criterion and convergent validity of the Automobile Anxiety Inventory. Steiner's AAI is a convenient instrument for a rapid and systematic 
assessment of driving anxiety, and it can serve as one of many helpful tools to define treatment objectives collaboratively for post-MVA patients.

\section{REFERENCES}

[1] Whetstone JP, Cernovsky Z, Tenenbaum S, Poggi G, Sidhu A, Istasy M, Dreer M. Validation of James Whetstone's Measure of Amaxophobia. Archives of Psychiatry and Behavioral Sciences. 2020;3(1):23-33.

[2] Weathers FW, Litz BT, Keane TM, Palmieri PA, Marx BP, Schnurr PP. The PTSD Checklist for DSM-5 (PCL-5). The National Center for PTSD, US Department of Veterans Affairs, Washington, DC, 2013. www.ptsd.va.gov.

[3] Eyres S, Carey A, Gilworth G, Neumann V, Tennant A. Construct validity and reliability of the Rivermead Post-Concussion Symptoms Questionnaire. Clinical Rehabilitation. 2005; 19:878-87.

[4] Cernovsky ZZ, Istasy PVF, Hernández-Aguilar ME, Mateos-Moreno A, Bureau Y, Chiu S. Quantifying Post-Accident Neurological Symptoms Other than Concussion. Archives of Psychiatry and Behavioral Sciences. 2019; 2(1):50-54.

[5] Morin CM, Belleville G, Bélanger L, Ivers H. The insomnia severity index: psychometric indicators to detect insomnia cases and evaluate treatment response. Sleep. 2011; 34:601-608.

[6] Cleeland CS. The Brief Pain Inventory - User Guide. Houston, TX: The University of Texas - M. D. Anderson Cancer Center, 2009.

[7] Pinfold M, Niere KR, O'Leary EF, Hoving JL, Green S, Buchbinder R. Validity and internal consistency of a Whiplash-Specific disability measure. Spine. 2004;29(3): 263-268.

[8] Steiner L, Cernovsky Z. Convergent Validity of Leon Steiner's Measure of Amaxophobia. Archives of Psychiatry and Behavioral Sciences. 2020;3(1):45-50.

[9] Cernovsky ZZ, Litman LC, Mann SC, Oyewumi LK, Bureau Y, Mendonça JD, Diamond DM, Raheb H. Validation of the Subjective Neuropsychological Symptoms Scale (SNPSS) in Injured Motorists. Archives of Psychiatry and Behavioral Sciences. 2021;4(1):6-13. doi: 10.22259/2638-5201.0401002.

[10] Taylor JE, Deane FP, Podd JV. Determining the focus of driving fears. Journal of Anxiety Disorders. 2000;14 (5): 453-70. doi:10.1016/s0887-6185(00)00033-5.

[11] Taylor J, Deane F, Podd J. Driving-related fear: a review. Clinical Psychology Review. 2002;22(5):631-645. doi:10.1016/s02727358(01)00114-3.

[12] Taylor JE. Understanding Driving-Related Fear. PhD Thesis in Psychology at Massey University, New Zealand, 2002.

[13] Taylor JE, Sullman MJ. What does the Driving and Riding Avoidance Scale (DRAS) measure? Journal of Anxiety Disorders. 2009;23(4):504-10. doi: 10.1016/j.janxdis.2008.10.006.

[14] Clapp JD, Olsen SA, Beck JG, Palyo SA, Grant DeMM, Gudmundsdottir B, and Marques L. The Driving Behavior Survey: Scale construction and validation. Journal of Anxiety Disorders. 2011; 25(1):96-105. doi: 10.1016/j.janxdis.2010.08.008.

[15] Ehlers A, Taylor JE, Ehring T, Hofmann SG, Deane FP, Roth WT, Podd JV. The Driving Cognitions Questionnaire: development and preliminary psychometric properties. Journal of Anxiety Disorders. 2007;21(4):493-509.

[16] Stewart AE, St Peter CC. Driving and riding avoidance following motor vehicle crashes in a non-clinical sample: psychometric properties of a new measure. Behavior Research and Therapy. 2004;42(8):859-879.

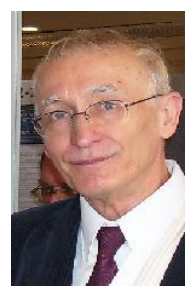

Zack Z. Cernovsky was born on January 26, 1947, in Czechoslovakia and holds the Ph.D. in clinical psychology from the University of Zürich, Switzerland, 1986.

He worked as a lecturer for the University of Maryland, European Division, as a psychologist in Canadian psychiatric hospitals, and is presently the professor of psychiatry in the medical school of Western University, Canada. He has published close to 200 scientific articles in medical and psychological journals and chapters in university textbooks. Professor Cernovsky is the life member of the American and Canadian Psychological Associations. 